\title{
Techniques for fabrication and construction of three-dimensional scaffolds for tissue engineering
}

This article was published in the following Dove Press journal:

International Journal of Nanomedicine

17 January 2013

Number of times this article has been viewed

Tingli Lu ${ }^{1, *}$

Yuhui $\mathrm{Li}^{1, *}$

Tao Chen ${ }^{1,2}$

'Key Laboratory of Space Bioscience and Biotechnology, School of Life

Science, Northwestern Polytechnical University, ${ }^{2}$ Liposome Research

Centre, Xi'an, China

*These authors contributed equally to this work
Correspondence: Tingli Lu

School of Life Science,

Northwestern Polytechnical

University, Xi'an 710072, China

$\mathrm{Tel}+86298849 \quad 1817$

$\mathrm{Fax}+862988460332$

Email lutinglixinxin@nwpu.edu.cn
Abstract: Three-dimensional biomimetic scaffolds have widespread applications in biomedical tissue engineering because of their nanoscaled architecture, eg, nanofibers and nanopores, similar to the native extracellular matrix. In the conventional "top-down" approach, cells are seeded onto a biocompatible and biodegradable scaffold, in which cells are expected to populate in the scaffold and create their own extracellular matrix. The top-down approach based on these scaffolds has successfully engineered thin tissues, including skin, bladder, and cartilage in vitro. However, it is still a challenge to fabricate complex and functional tissues (eg, liver and kidney) due to the lack of vascularization systems and limited diffusion properties of these large biomimetic scaffolds. The emerging "bottom-up" method may hold great potential to address these challenges, and focuses on fabricating microscale tissue building blocks with a specific microarchitecture and assembling these units to engineer larger tissue constructs from the bottom up. In this review, state-of-the-art methods for fabrication of three-dimensional biomimetic scaffolds are presented, and their advantages and drawbacks are discussed. The bottom-up methods used to assemble microscale building blocks (eg, microscale hydrogels) for tissue engineering are also reviewed. Finally, perspectives on future development of the bottom-up approach for tissue engineering are addressed.

Keywords: three-dimensional, extracellular matrix scaffolds, bottom-up, tissue engineering

\section{Introduction}

In the last decade, various fabrication methods for construction of three-dimensional biomimetic scaffolds, including electrospinning, ${ }^{1-3}$ phase-separation, ${ }^{4,5}$ freeze drying, ${ }^{6,7}$ and self-assembly, ${ }^{8,9}$ have been developed for tissue engineering and regenerative medicine. These scaffolds can mimic the architecture of the native extracellular matrix at the nanoscale level (eg, hierarchical architecture formed with nanofibers and nanopores), which provides the initial space for regeneration of new tissue. ${ }^{10} \mathrm{In}$ addition, surface modification methods (eg, plasma exposure) used for nanostructured scaffolds can introduce functional groups (eg, Arg-Gly-Asp peptide) onto the surface of the scaffolds, which directly and significantly enhance cell attachment, migration, and proliferation.

Traditional tissue engineering methods use a "top-down" approach, in which cells are seeded onto a scaffold with biocompatible and biodegradable properties, and are expected to populate in the scaffold and create their own extracellular matrix. Despite several thin or avascular tissues, such as skin, ${ }^{11}$ bladder, ${ }^{12}$ and cartilage,${ }^{13}$ having been engineered successfully via the top-down approach based on these biomimetic scaffolds in vitro, the fabrication of complex larger functional tissues (eg, liver and kidney) 
with high cell densities and high metabolic requirements still faces challenges. This is mainly because of the limited diffusion properties of biomimetic scaffolds. ${ }^{14}$ For instance, the diffusion scale of hydrogel scaffolds is often restricted to $200 \mu \mathrm{m}$ due to the necrotic core. ${ }^{15,16}$ Currently, the emerging "bottom-up" method may hold great potential to address this challenge, and focuses on the fabrication of microscale tissue building blocks with a specific microarchitecture and assembling these units to engineer larger tissue constructs from the bottom up. ${ }^{17}$ Fabrication of tissue building blocks can be achieved via multiple approaches, including fabrication of cell-encapsulating microscale hydrogels (microgels), self-assembled cell aggregation, generation of cell sheets, and direct printing of cells ${ }^{18-20}$ (Figure 1). These microscale building blocks can be successfully assembled into complex tissue constructs, with control over features such as the shape and composition of individual blocks. ${ }^{21,22}$ Various assembly methods have been investigated, including those based on microfluidics, ${ }^{23}$ acoustic fields, ${ }^{24}$ magnetic fields, ${ }^{25}$ and surface tension. ${ }^{26}$

In this review, we firstly describe state-of-the-art methods for fabricating nanofibrous biomimetic scaffolds, including electrospinning, phase-separation, freeze-drying, and self-assembly. A brief overview of their applications for tissue engineering is also presented. Secondly, the bottom-up methods for assembling microscale blocks (eg, microgels) including railed microfluidic assembly, surface tension assembly, acoustic assembly, and magnetic assembly are reviewed. Moreover, microfluidic hydrogels for vascularization are briefly presented. Finally, future perspectives for the development of techniques of construction of threedimensional scaffolds are offered.

\section{Fabrication of three-dimensional biomimetic scaffolds}

Many extracellular proteins, including collagen, have a nanoscale fibrous structure $(50-500 \mathrm{~nm}$ in diameter) in vivo, which has been found to enhance cell attachment, proliferation, and differentiation. ${ }^{27,28}$ Nanofibrous biomimetic scaffolds consist of biodegradable polymer nanofibers, which can be fabricated by several methods, including electrospinning, phase-separation, and self-assembly, and can mimic the nanofibrillar structure of the extracellular matrix in vivo. Here, we focus on these fabrication methods
A

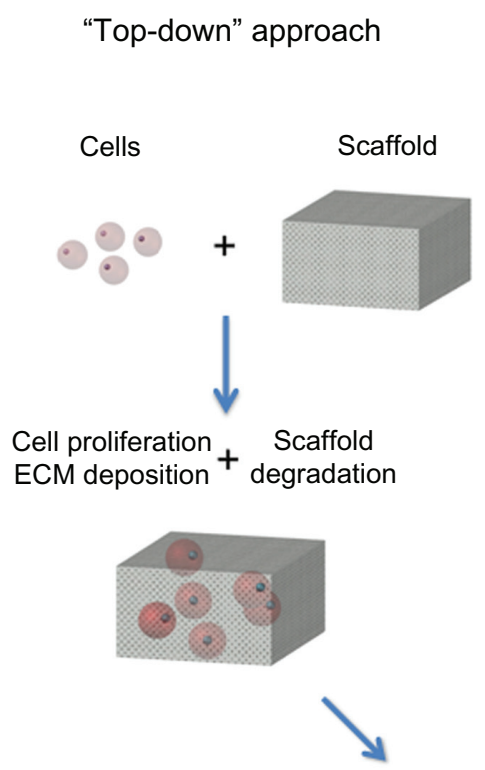

B

"Bottom-up" approach

Cell-encapsulating Cell Cell Cell microgels aggregation Sheet printing

Engineered tissue
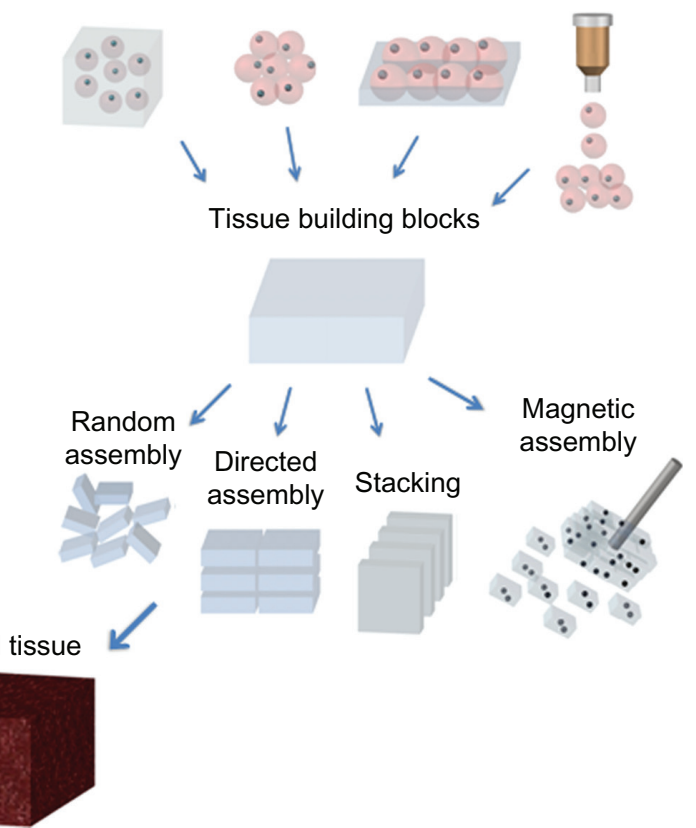

Figure I Schematic of "top-down" and "bottom-up" approaches for tissue engineering. (A) In the top-down approach, cells are seeded on a biocompatible and biodegradable scaffold and are expected to populate in the scaffold and create their own extracellular matrix. (B) In the bottom-up approach, various methods are utilized for generating tissue building blocks and these units can be engineered into large tissue constructs via multiple assembling methods. Abbreviation: ECM, extracellular matrix. 
for nanofibrous scaffolds and their successful applications in tissue engineering (Table 1).

\section{Electrospinning}

Electrospinning is a technique used widely for fabricating fibers with diameters in the nanoscale $(<1000 \mathrm{~nm})$ or microscale $(>1 \mu \mathrm{m})$ range..$^{29}$ In the electrospinning process, a syringe pump, a high voltage source, and a collector are needed (Figure 2A). Firstly, a very high voltage is applied to a capillary tube filled with polymer solution or melt, which is held at the tip of the capillary via surface tension. Secondly, a mutual charge repulsion caused by application of an electrical field is induced within the polymer solution or melt, which directly opposes the surface tension of the polymer solution. When the intensity of the electrical field is increased, the charge repulsion will overcome the surface tension to form a jet. Finally, the ejected polymer solution and melt repel each other and the solvent evaporates to form fibers as the jet travels to the collector. Fibers ranging from nanometers to micrometers in size can be formed by regulating parameters including intrinsic solution properties, eg, viscosity, conductivity, and surface tension, and operational conditions, including the hydrostatic pressure in the capillary tube, strength of the electrical field applied, and distance between the tip and collector.

A variety of synthetic polymers, eg, poly(lactic acid) [PLLA], poly(glycolic acid), poly(lactic-co-glycolic acid) [PLGA] and polycaprolactone, and natural polymers (eg, collagen, chitosan, silk fibroin, and chitin) have been fabricated as three-dimensional nanofibrous scaffolds using the electrospinning method for tissue engineering. ${ }^{30-32}$ For instance, electrospinning of type I collagen in 1,1,1,3,3,3hexafluoro-2-propanol solvent to fabricate biomimetic nanofibrous scaffolds has been investigated ${ }^{33}$ (Figure 2B). The average diameter of electrospun collagen fibers was
$460 \mathrm{~nm}$, and they were found to enhance cell attachment, growth, and proliferation after the coating process with extracellular matrix proteins (type I collagen or laminin). For synthetic polymers with poor biocompatibility, various macromolecules, such as proteins and growth factors, can be incorporated into nanofibrous scaffolds to enhance their biocompatibility during the electrospinning process. ${ }^{34,35}$ Although electrospinning is a quick and simple approach to fabrication of various types of nanofibrous scaffolds, it is still a big challenge to engineer scaffolds with complex structures for many tissue engineering applications. Moreover, generation of scaffolds containing a homogeneous distribution of pores will also need to be addressed.

\section{Phase separation}

The phase separation process can be induced thermally or by a nonsolvent, and has been utilized to fabricate porous membranes or foams for filtration and separation purposes. ${ }^{36}$ Induction of the phase separation process using a nonsolvent commonly results in scaffolds with a heterogeneous pore structure which is not suitable for fabrication of tissue engineering scaffolds, which generally need a uniform pore structure. ${ }^{37}$ The thermally induced phase separation process takes place when a homogeneous polymer solution becomes thermodynamically unstable under certain temperature conditions and tends to separate into a multiphase system domains, comprising a polymer-lean phase (with a low polymer concentration) and a polymer-rich phase (with a high polymer concentration). ${ }^{38,39}$ Subsequently, the polymer-rich phase solidifies to form a matrix while the polymer-lean phase turns into pores as a result of solvent removal. Thermally induced phase separation can be divided into solid-liquid phase separation and liquid-liquid phase separation. The solid-liquid phase separation process is used to induce solvent crystallization from a polymer solution by lowering the
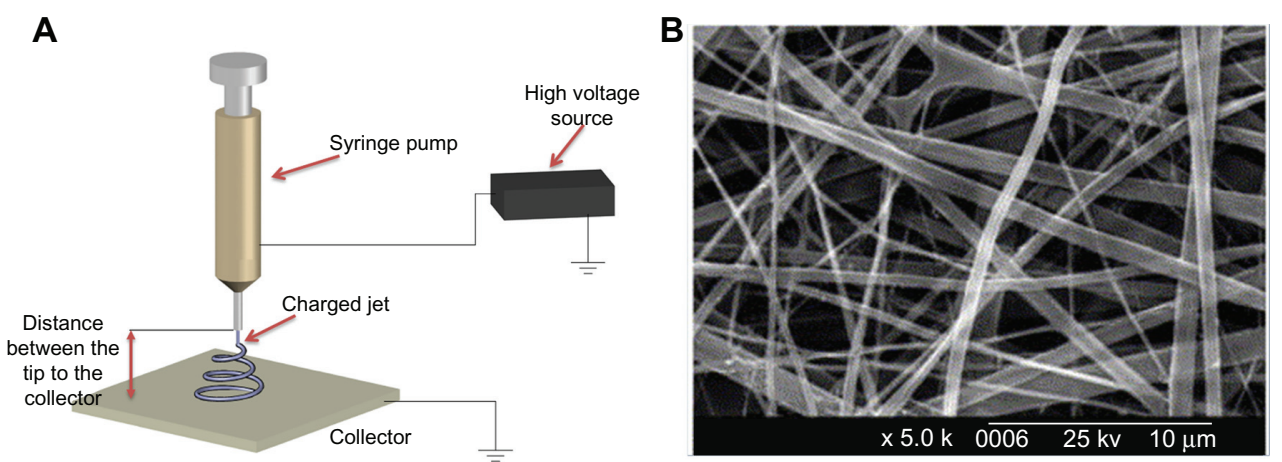

Figure 2 Electrospinning technique for three-dimensional biomimetic scaffold fabrication. (A) Schematic of electrospinning technique and (B) scanning electron microscopic images of collagen nanofibers fabricated by electrospinning. ${ }^{33}$ 
temperature, which leads to formation of pores after removal of solvent crystals. In the liquid-liquid phase separation process, polymer solutions with an upper critical temperature form a bicontinuous structure (both polymer-lean phase and polymer-rich phase). ${ }^{40,41}$

Various synthetic polymeric nanofibers have been fabricated using phase separation methods for tissue engineering applications. ${ }^{4,5}$ For instance, PLLA scaffolds with a continuous three-dimensional nanofibrous network have been fabricated using liquid-liquid phase separation, which contained nanofibers with a diameter ranging from $50 \mathrm{~nm}$ to $500 \mathrm{~nm}$ and a porosity of $98 \%{ }^{42}$ PLLA/hydroxyapatite porous scaffolds have also been prepared using solid-liquid phase separation, and demonstrated to enhance osteoblast growth and proliferation better than pure PLLA scaffolds in bone tissue engineering. ${ }^{43}$ Recently, several natural polymers have been fabricated into three-dimensional porous scaffolds. For instance, chitosan scaffolds with nanofibrous or microfibrous structures have been prepared by solid-liquid phase separation. The porosity and fiber size of the scaffolds can be regulated by several methods, including phase separation temperature and chitosan concentration, which will be a potential tool for tissue engineering ${ }^{44}$ (Figure $3 \mathrm{~A}$ and $\mathrm{B}$ ). Compared with the electrospinning approach, phase separation holds great potential for fabrication of three-dimensional nanofibrous scaffolds with uniform pore structures through dual or multiple phase separation processes. In addition, phase separation can engineer three-dimensional shapes via several techniques, including solid free-form fabrication, rapid prototyping, and computer-assisted design and manufacture. However, limitations such as limited material selection and inadequate resolution still exist.

\section{Freeze-drying}

Freeze-drying has emerged as a drying process for converting solutions of labile materials into solids of sufficient stability for distribution and storage in applications such as food science, pharmaceuticals, and enzyme stabilization. ${ }^{45-47}$ Freezedrying involves three major steps: the solution is frozen at a low temperature $\left(-70^{\circ} \mathrm{C}\right.$ to $\left.-80^{\circ} \mathrm{C}\right)$; the frozen sample is located in a chamber in which the pressure is lowered (to a few millibars) through a partial vacuum, known as the primary drying process, in which ice in the material is removed by direct sublimation; and most of the unfrozen water in the material is removed by desorption in a secondary drying process. In the last two decades, the freeze-drying method has been widely investigated for the fabrication of threedimensional porous scaffolds for tissue engineering. ${ }^{7,48}$ For instance, methacrylamide-modified gelatin-2-hydroxyethyl methacrylate porous scaffolds have been fabricated using the
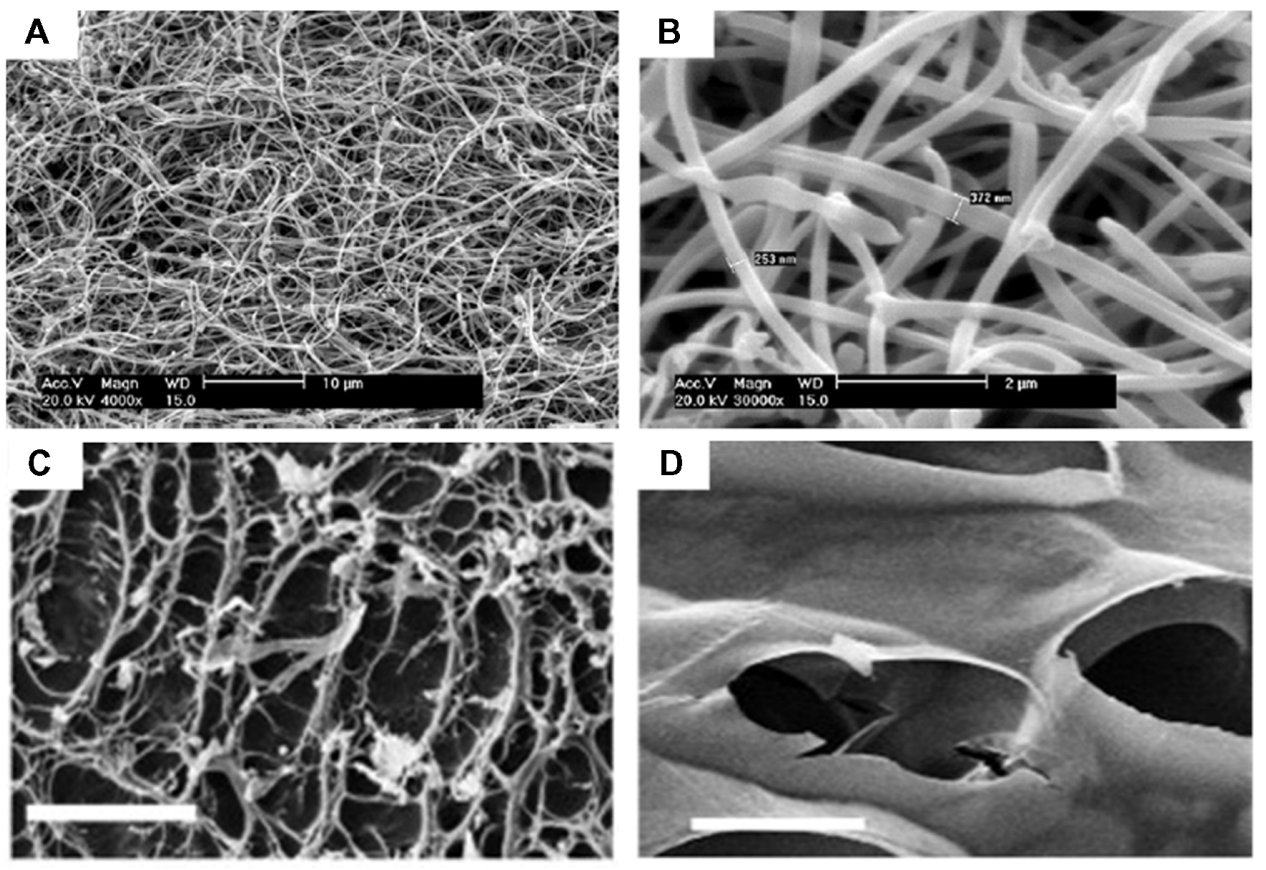

Figure 3 Scanning electron micrographs of nanostructured scaffolds fabricated by phase-separation and freeze-drying. (A and $\mathbf{B}$ ) Images of chitosan nanofibers prepared by phase-separation at $0.05 \%(\mathrm{w} / \mathrm{v})$ chitosan, $0.025 \%(\mathrm{w} / \mathrm{v})$, and liquid nitrogen (A, scale bar $10 \mu \mathrm{m}$; B, scale bar $2 \mu \mathrm{m}){ }^{44}$ Images of porous scaffolds prepared by freeze-drying under $6.5 \mathrm{mbar}(\mathbf{C})$ and $0.1 \mathrm{mbar}(\mathbf{D})$ freeze-drying pressure (scale bar, $50 \mu \mathrm{m}){ }^{48}$ 
freeze-drying method. ${ }^{49}$ Human foreskin fibroblasts seeded onto these novel scaffolds still maintain high (95\%) viability after 7 days in culture in vitro. Autissier et $\mathrm{al}^{48}$ prepared a porous polysaccharide-based scaffold using the freeze-drying method, and demonstrated that pore diameter $(55-243 \mu \mathrm{m})$ and porosity $(33 \%-68 \%)$ in the scaffolds can be regulated by the freeze-drying pressure (Figure $3 \mathrm{C}$ and $\mathrm{D}$ ). Adhesion and proliferation of human mesenchymal stem cells on both porous and nonporous polysaccharide-based scaffolds have also been investigated. Although there are several advantages of the freeze-drying method, including use of water and ice crystals instead of an organic solvent in the scaffold fabrication process, which is more suitable for biomedical applications, it is still a big challenge to engineer scaffolds with hierarchical structures (eg, vascularized systems) using this approach.

\section{Self-assembly}

The self-assembly process, defined as an autonomous organization of components into patterns or structures without human intervention, has been utilized for fabrication of various nanofibers. ${ }^{50,51}$ Such self-assembly of biological molecules can be induced by noncovalent bonds or weak covalent interactions, including electrostatic, van der Waals, hydrophobic interactions, ionic, hydrogen, and coordination bonds. A typical example of molecular self-assembling into an ordered structure in nature is phospholipids, which are important components of the cell membrane and can selfassemble into several higher order structures such as vesicles, tubules, and micelles in aqueous solution due to their natural amphiphilic structures. ${ }^{52}$ In addition, various nanoscale filaments of proteins (eg, peptides) can be assembled into nanofibers with a high aspect ratio, which can mimic the physical microenvironment of cells in vivo. In the body, these nanofibers could wrap around cells covering long distances over their surfaces and act as cables that connect neighbor cells and mechanically support them by creating three-dimensional networks ${ }^{53}$ (Figure 4A). For instance, one kind of peptide amphiphiles has been investigated to fabricate nanofibers via a $\mathrm{pH}$-induced self-assembly process for bone tissue engineering. ${ }^{54}$ These peptide amphiphiles contains several key structural features, including: long hydrophobic alkyl tails that aggregate in aqueous solution to drive self-assembly; four consecutive cysteine residues that form disulfide bonds to polymerize the self-assembled structures; a linker region of three glycine residues to provide flexibility to the hydrophilic head group; a single phosphorylated serine residue that interacts strongly with calcium ions to enhance mineralization; and a Arg-Gly-Asp peptide ligand to enhance cell adhesion ${ }^{55}$ (Figure 4B). Peptide amphiphiles treated with dithiothreitol at $\mathrm{pH} 8$ are soluble in aqueous solution and start to self-assemble at $\mathrm{pH} 4$. Fibers with an average diameter of $7 \mathrm{~nm}$ and length of up to several micrometers are formed and can be observed by cryotransmission electron microscopy (Figure 4C). Moreover, a class of peptide amphiphiles has been demonstrated to self-assemble into nanofiber networks by adjusting both the $\mathrm{pH}$ and salt ion concentration (eg, sodium and potassium) in aqueous solution.

In addition to peptide amphiphiles, various designer oligopeptides can also self-assemble into nanofibers as a result of their amphiphilic structure. ${ }^{56,57}$ The first of the designer oligopeptides, EAK 16-II, a 16-amino acid peptide, was found as a segment in zuotin, a yeast protein, which was originally characterized as binding to left-handed Z-DNA. ${ }^{58}$ This natural peptide had an amino acid sequence of AEAEAKAKAEAEAKAK, which can form a stable $\beta$-sheet structure and self-assemble into hydrogels with various shapes upon adjustment of the sodium/potassium concentration in aqueous solution. These peptide scaffolds can enhance mammalian cell adhesion, proliferation, and differentiation. ${ }^{59,60}$ Holmes et $\mathrm{a}^{61}$ studied neuronal cell adhesion and differentiation using Ac-RADARADARADARADA-NH2 (RAD16-I) and Ac-RARADADARARADADA-NH2 (RAD16-II), two short self-assembling peptide hydrogel scaffolds, and found that mouse neurons can form active dendrites on these scaffolds.

Although the self-assembly approach can form various types of nanofibers and nanoscale networks upon adjustment of sample parameters, such as the $\mathrm{pH}$ and ionic concentration of the aqueous solution, it is still a challenge to form stable three-dimensional geometrical structures due to their poor mechanical properties and the fact that the engineered peptide nanofibers can be fragmented and are susceptible to endocytosis. ${ }^{44}$ Moreover, the high cost of synthesis of biomaterials limits their applications in tissue engineering and regenerative medicine.

\section{Nanofibrous scaffolds in tissue engineering}

\section{Extracellular matrix mimics}

The extracellular matrix is a complex three-dimensional network for cell growth, proliferation, and differentiation, which consists of a cellular matrix of nanofibers with nanopores that create various local microenvironments. ${ }^{51}$ Nanofibrous scaffolds can be utilized as superior extracellular matrix mimics for tissue engineering applications because of 

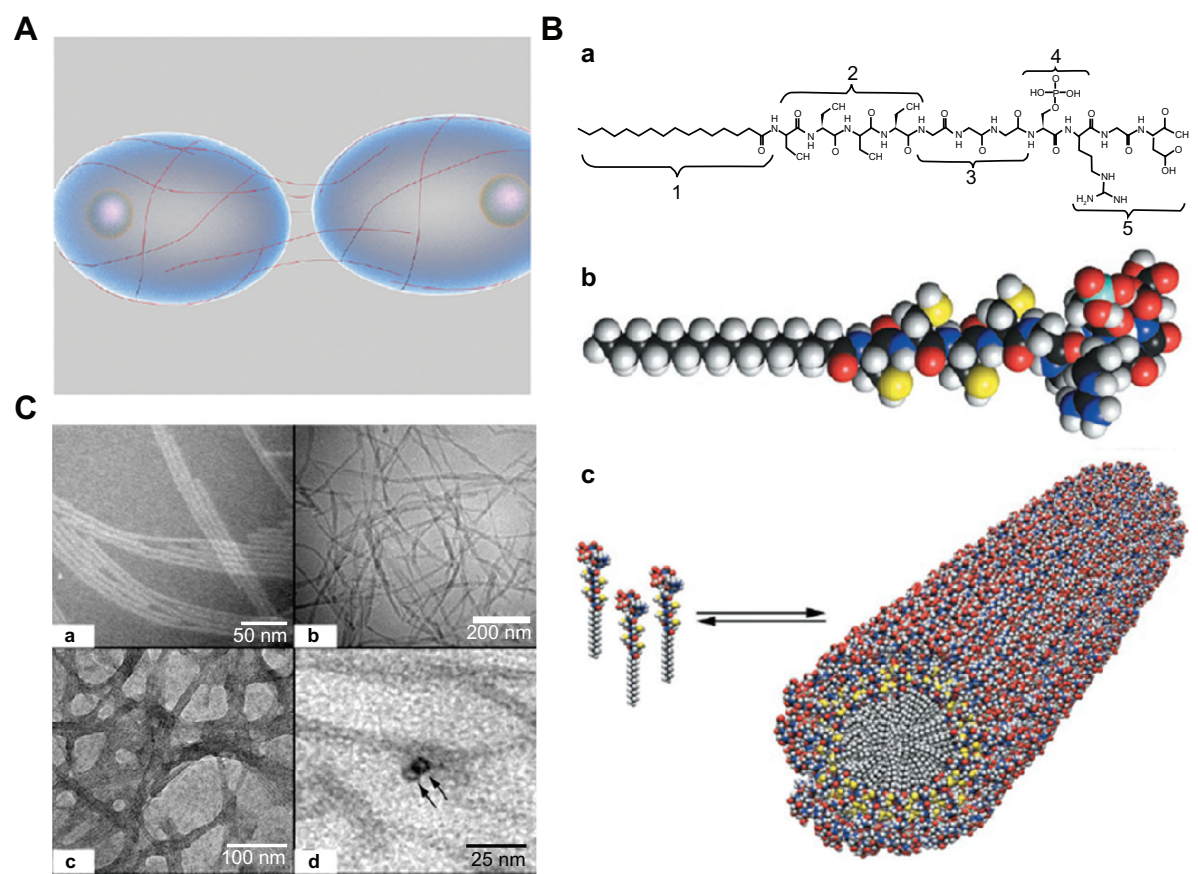

Figure 4 Self-assembly method for fabrication of three-dimensional scaffolds. (A) Schematic representation of filamentous nanostructures surrounding cells for signaling events. ${ }^{53}$ (B) (a) Chemical structure and (b) molecular model of peptide amphiphiles. Color scheme: C, black; H, white; O, red; N, blue; P, cyan; S, yellow. (c) Schematic for the self-assembly of peptide amphiphiles into a cylindrical micelle. (C) (a and b) Transmission electron microscopic images of self-assembled nanofibers before covalent capture. (a) Scale bar $50 \mathrm{~nm}$ and (b) scale bar $200 \mathrm{~nm}$. (c and d) Transmission electron microscopic images of self-assembled nanofibers after oxidative crosslinking (c, scale bar $100 \mathrm{~nm}$; d, scale bar $25 \mathrm{~nm}$ ). ${ }^{55}$

their architectural features, which are similar to those of the extracellular matrix in vivo. Firstly, nanofibrous scaffolds consisting of nanofibers are similar to most extracellular matrix molecules, such as matrix proteins (eg, collagen, laminin, and fibronectin, $5-500 \mathrm{~nm}$ in size) and proteoglycans (eg, hyaluronic acid, 450-1000 nm), which have been found to enhance cell attachment, proliferation, and differentiation. ${ }^{62}$ Secondly, in a true three-dimensional environment in vivo, the pores generated by nanofibers in the extracellular matrix are much smaller than the diameter of most cells $(5-50 \mu \mathrm{m})$ and have high porosity $(>80 \%)$. Nanofibers in three-dimensional biomimetic scaffolds can have variable porosity (60\%-95\%), with diameters ranging from nano size to micro size, which can be controlled using several fabrication methods, as described earlier. Thus, these scaffolds can mimic the extracellular matrix in vivo with adjustable pore structures. Finally, the stiffness of native tissues, which is the most common mechanical cue that cells are exposed to in vivo, ranges from $0.1 \mathrm{kPa}$ (eg, in the brain) to $40 \mathrm{kPa}$ (eg, in osteoid tissue). ${ }^{63}$ Although scaffolds composed of natural polymers are usually mechanically weak and have limited mechanical controllability, several methods have been developed to improve their mechanical performance, including incorporation of functional groups (eg, thiolate, acrylate, and tyramine), and several composition systems, eg, collagen-polyacrylamide, alginate-polyacrylamide, and agarose-poly(ethylene glycol)
(PEG) have been generated. ${ }^{64,65}$ For instance, human mesenchymal stem cells show neurogenic and osteogenic phenotypes when seeded onto collagen-polyacrylamide hydrogel scaffolds, with a stiffness similar to that in brain $(0.1-1 \mathrm{kPa})$, muscle $(8-17 \mathrm{kPa})$, and nascent bone (>34 kPa) tissue. ${ }^{66}$ Therefore, nanofibrous scaffolds hold great potential as in vivo extracellular matrix mimics for tissue engineering applications.

\section{Top-down approach for tissue engineering}

The top-down approach based on a variety of threedimensional scaffolds has been investigated for application in tissue engineering, due to the nanoscale structure of these scaffolds being analogous to that of the native extracellular matrix. For instance, in vascular tissue engineering, fabrication of small diameter (inner diameter $<6 \mathrm{~mm}$ ) vascular grafts to meet clinical needs is still a big challenge, mostly due to the potential for thrombus formation. To address this challenge, Liu et a ${ }^{67}$ fabricated sulfated silk fibroin nanofibrous scaffolds (S-silk scaffold) with enhanced anticoagulant activity to reduce platelet adhesion and aggregation in denuded areas on the luminal surface of vascular grafts, which may prevent thrombus formation and improve the chances of successful vascular reconstruction in small vessels. The nanofibrous scaffold was engineered using an electrospinning method, and was composed of continuous nanofibers 
with an average diameter of $220 \pm 35 \mathrm{~nm}$. In addition, both adhesion and proliferation of endothelial cells on S-silk scaffolds were investigated in vitro. It was found that the anticoagulant activity of S-silk scaffolds was significantly improved compared with that of silk fibroin nanofibrous scaffolds. For engineering of cartilage tissue, the major limitation of currently engineered cartilage is its nonhomogeneous structure and poor mechanical properties. It has also been demonstrated that oriented scaffolds (similar to cartilage tissue in vivo) could greatly improve cell migration compared with the nonoriented scaffolds achieving cartilage regeneration in vitro. Thus, how to engineer three-dimensional scaffolds with regulated oriented structures and the desired mechanical properties is still a challenge. Recently, Zhang et a ${ }^{68}$ fabricated a PLGA scaffold with highly porosity (90\%) and a microtubule structure using a solid-liquid phase separation approach. Oriented scaffolds seeded with chondrocytes formed thicker cartilage with a more homogeneous structure and stronger mechanical properties than nonoriented scaffolds after 12 weeks of in vitro culture. Furthermore, cartilage engineered in vitro was implanted into nude mice and showed a mature structure, with abundant cartilage-specific extracellular matrix deposition after 12 weeks (Figure 5).

Conventional approaches to engineering tissues based on three-dimensional biomimetic scaffolds in vitro involve three steps: fabrication of three-dimensional scaffolds via various techniques including electrospinning, phase separation, freeze-drying, and self-assembly; surface modification of the prepared scaffolds to enhance their biocompatibility, especially of their synthetic polymer components; and coculture of cells on three-dimensional porous scaffolds to regenerate tissues in vitro. ${ }^{22}$ Although several thin or avascular tissues (eg, skin, bladder, and cartilage) have been engineered successfully via the top-down strategy in vitro, fabrication of complex and large functional tissues (eg, liver and kidney) with high cell densities and high metabolic requirements still faces challenges. This is mainly because of the limited diffusion properties of biomimetic scaffolds. ${ }^{69}$ Another key challenge of these scaffolds is the lack of an adequate vasculature system to supply oxygen and nutrients for tissues in vivo and eliminate the waste they generate. ${ }^{70,71}$ Therefore, strategies to address these challenges are urgently needed to engineer complex and large functional tissues in vitro for clinical applications.

\section{Bottom-up approach for tissue engineering}

Hydrogels have widespread applications in biomedical engineering because of their hydrated environment and tunable mechanical, chemical, and biocompatibility properties which are similar to the native extracellular matrix. ${ }^{72}$ Recently, the bottom-up approach has emerged as an assembly process for microscale building blocks (eg, cell-encapsulating microgels)
A
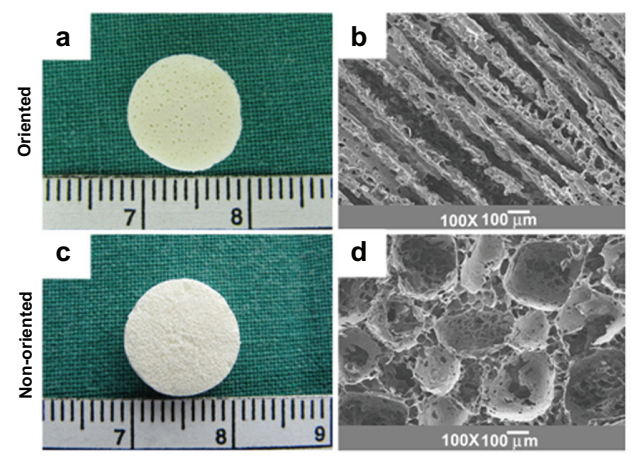

e

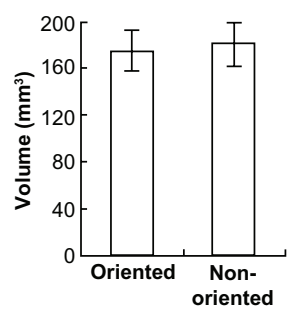

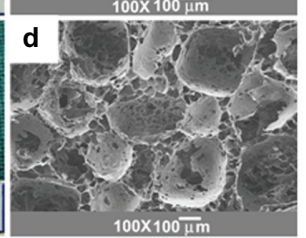

f

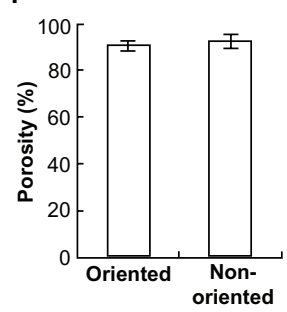

B
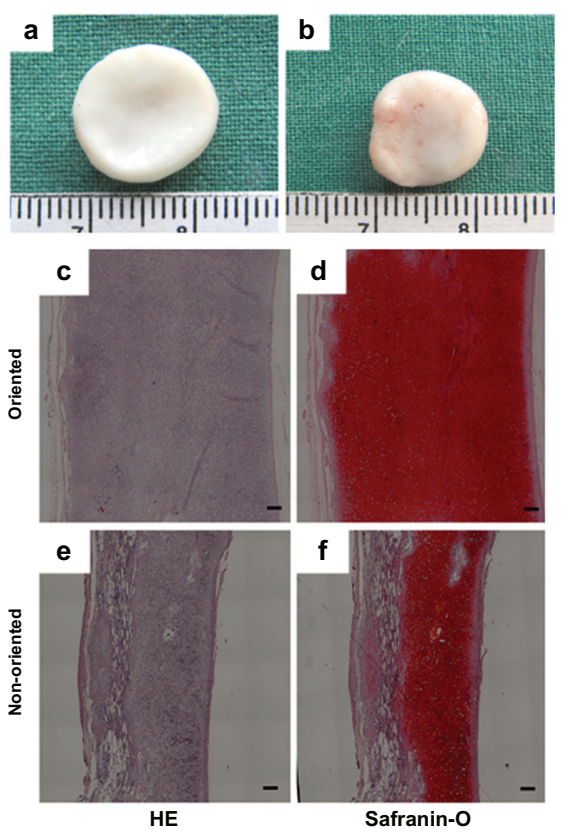

Figure 5 Three-dimensional biomimetic scaffolds for cartilage tissue engineering. ${ }^{68}$ (A) Actual and scanning electron micrographs of oriented (a and $\left.\mathbf{b}\right)$ and nonoriented scaffolds (c and d) showing the volume and porosity of each scaffold (e and f). (B) In vivo fate of in vitro fabricated cartilage: grow view (a and b), histology and immunohistochemistry; the specimen in the oriented group shows typical and homogeneous cartilage structure with abundant cartilage-specific extracellular matrix and a large size in thickness (c and d); the specimen in the nonoriented group shows relatively heterogeneous cartilage structure with a smaller thickness $(\mathbf{e}$ and $\mathbf{f})$. Scale bar $100 \mu \mathrm{m}$. 
which holds great potential to fabricate complex tissue constructs, with control over the shape and compositional features of the individual building blocks. ${ }^{24,25,73,74}$ Another advantage of the bottom-up method is the superior diffusion properties of microgels due to their controllable volume, which can obtain a high cell density after encapsulating cells. A variety of methods have been developed to fabricate microgels, including molding, ${ }^{75}$ folding, photolithography, ${ }^{21}$ molecular synthesis, ${ }^{76}$ and generation of microdroplets. ${ }^{77}$ Here we focus on microgels fabricated using photolithography (Figure 6A) and the assembly approaches used for these microgels via railed microfluidic assembly, surface tension assembly, acoustic assembly, and magnetic assembly. A brief review of fabrication methods for microfluidic hydrogels with vascular-like structures is now be presented.

\section{Strategies for assembly of microscale hydrogels Trailed microfluidic assembly}

Microfluidic assembly is a promising process for parallel fabrication of devices based on microfluidic channels. ${ }^{78,79}$
Recently, a novel railed microfluidic assembly approach was utilized to assemble microgels, involving fabrication of two-dimensional complex constructs, such as a Greek temple shape ${ }^{23}$ (Figure 6B). In this study, a groove was fabricated on the top surface of the microfluidic channel instead of a conventional channel with a flat surface, which functioned as a rail to guide the movement of in situ photocrosslinking hydrogel precursor solutions. The main advantage of this approach is its capacity to assemble complex constructs (eg, Greek temple, Eiffel tower, and skeleton shapes) composed of a large number of different parts, just by increasing the number of rails and microstructures involved in the assemble process. In addition, heterogeneous assembly of microstructures comprising different polymeric materials was achieved by cross-solution movement. A $3 \times 3$ microgel matrix encapsulating two types of living cells (HeLa and HEK293) was also formed using trailed microfluidic assembly. The results indicate that the microfluidic assembly approach could be a useful tool for fabricating complex constructs with multiple cell types for tissue engineering.
A

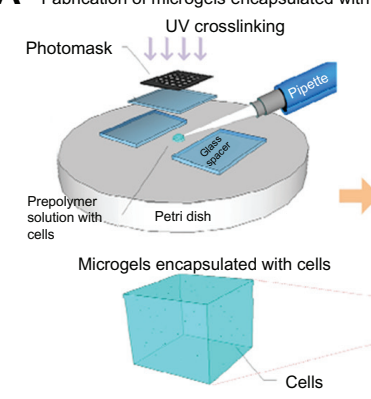

C a

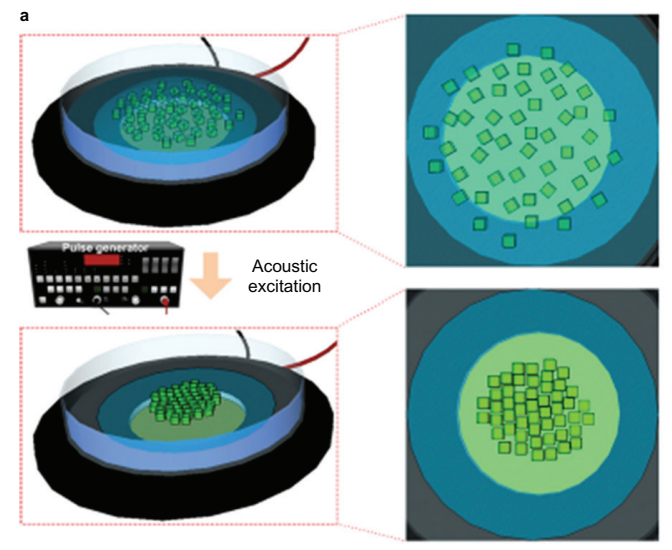

$B_{A}$
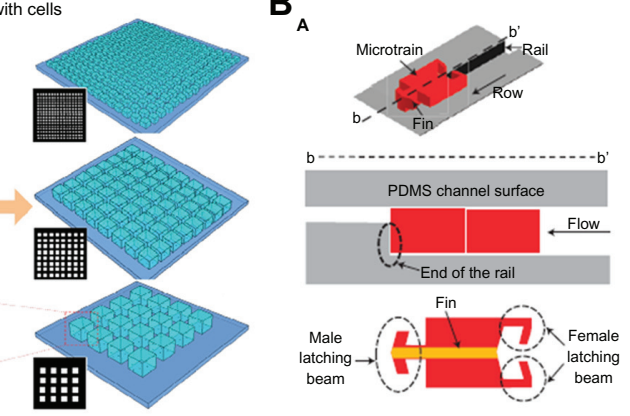

Before acoustic excitation
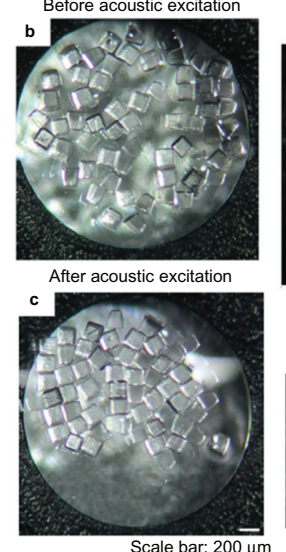
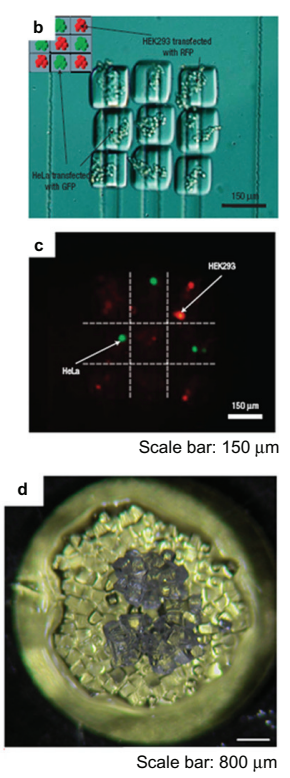

Scale bar: $800 \mu \mathrm{m}$

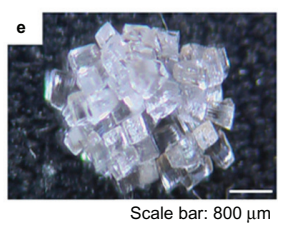

Figure 6 Fabrication and assembly process for microgels via railed microfluidic and acoustic field. (A) Schematic of photolithography methods used to fabricate microgels. ${ }^{87}$ (B) Railed microfluidic assembly of microgels, (a) schematic of a microtrain, (b) assembled $3 \times 3$ matrix with two different living cells using cell-encapsulating thylene glycol diacrylate solution, and (c) fluorescent images of cell-encapsulating microgels. Scale bar $150 \mu \mathrm{m} .{ }^{23}$ (C) (a) Schematic of acoustic assembly of microgels; (b and c) before and after acoustic excitation, single-layer formation $(200 \mu \mathrm{m} \times 200 \mu \mathrm{m}$ microgels, scale bar $200 \mu \mathrm{m})$; (d) new microgels were introduced onto a single layer to generate a doublelayered structure (scale bar $200 \mu \mathrm{m}$ ); (e) multilayered structure using layer-to-layer approach (scale bar $200 \mu \mathrm{m}$ ). ${ }^{24}$ 


\section{Acoustic assembly}

Acoustic techniques, such as ultrasonic standing waves integrated with microfluidics, have traditionally been used for manipulation of particles and cells, cell synchronization, cell patterning, and microcentrifugation. ${ }^{80,81}$ Acoustic techniques have several advantages, including noninvasive and gentle handling of cells and particles that are sensitive to pressure or heat and reduced instrumentation complexity. ${ }^{82}$ Recently, an assembly approach of cell-encapsulating microgels using acoustic fields has been developed ${ }^{24}$ (Figure 6C). Firstly, microgels were fabricated by a photocrosslinking reaction of PEG-methacrylate hydrogel precursor solution mixing with both photoinitiator and cell suspensions. In this study, 2-hydroxy-1-(4-(hydroxyethoxy) phenyl)-2-methyl-1-propanone (Irgacure 2959) was utilized as a cytocompatible photoinitiator to generate initiating radicals of PEG-methacrylate monomers, which can ultimately form crosslinked networks due to the two acrylate double bonds existing in the structure. A variety of PEG-based hydrogels, which have widespread applications for cell/drug encapsulation, can be formed via a photocrosslinking reaction due to simple modification of the end groups on PEG. For instance, the reaction of PEG with methacryloyl chloride or acryloyl chloride in the presence of triethylamine is a simple method for adding photoreactive vinyl groups ${ }^{83-85}$ At this stage, both ultraviolet light and a photomask were needed. Secondly, microgels with maintained cell viability $(>93 \%)$ and various sizes and geometries (eg, square, tetris, lock-and-key) were assembled to form a single-layer structure in seconds in a noninvasive manner. The single-layer structure was stabilized by secondary crosslinking. Finally, new microgels were introduced onto the surface of the assembled single-layer structure and then assembled to form a second-layer structure using an acoustic field. Multilayer constructs were also generated using this layer-by-layer approach.

\section{Surface tension assembly}

Despite the two-dimensional complex constructs being able to be fabricated via the railed microfluidic assembly approach, assembly of cell-encapsulating microgels into three-dimensional tissue constructs is still needed for tissue engineering. To address this challenge, a novel assembly of microgels has been developed, driven by the thermodynamic tendency of multiphase liquid-liquid systems to minimize the surface area and obtain a lower energy configuration ${ }^{21}$ (Figure 7B). First, PEG-methacrylamide microgels were fabricated via photopolymerization (as mentioned earlier) and located into hydrophobic mineral oil phase, with four types of microgels, including linear, random, branched, and offset, obtained by adjusting the agitation rate. Next, a secondary crosslinking step was needed to stabilize the assembled constructs outside of mineral oil phase, and a lock-and-key shape of microgels was observed in the final assembly. Finally, the viability of NIH 3T3 cells encapsulated in the microgels was evaluated. The cell-encapsulating microgels fabricated after initial crosslinking and secondary crosslinking still maintained high cell viability of $95 \%$ and $85 \%$, respectively. The surface tension assembly approach was also developed by using a more hydrophobic organic solvent (perfluorodecalin) to fabricate three-dimensional tissue constructs with adjustable features in the micrometer scale. The high hydrophobicity of the solvent resulted in enhanced surface tension and closely packed microgels at the liquid-air interface. ${ }^{26,74}$ The assembly process could also be controlled by changing the stirring speed and duration. Comparing with the railed microfluidic assembly approach, emerging surface tension assembly strategies hold great potential for fabrication of organized complex three-dimensional tissue constructs with spatial control in vitro.

\section{Magnetic assembly}

Magnetic hydrogels have widespread applications in drug delivery, enzyme immobilization, and cancer therapy due to their controllability, actuation, and rapid response properties, as a result of interactions between embedded magnetic nanoparticles and an external magnetic field. In addition, microgels with embedded magnetic nanoparticles have been utilized for three-dimensional cell culture. Using this approach, it has been demonstrated that control of tissue shape and in situ monitoring of interaction in a confrontation assay can be achieved. ${ }^{86}$

Recently, a novel assembly method involving application of an external magnetic field to assemble cell-encapsulating microscale magnetic hydrogels (M-gels) has been developed ${ }^{25}$ (Figure 7A). In this approach, three-dimensional multilayer spherical constructs were obtained by assembling M-gels (gelatin methacrylate) onto the tip of a magnetic rod, layer by layer. The size of the spherical constructs assembled can be precisely adjusted by the concentration of the magnetic nanoparticles in the M-gels. Fabrication of other complex three-dimensional constructs, including arc and dome shapes, was also achieved successfully. Release of magnetic nanoparticles encapsulated in M-gels as the hydrogel network undergoes biodegradation has also been evaluated using inductively coupled plasma atomic emission spectroscopy. ${ }^{87}$ This demonstrated that release of the magnetic nanoparticles 
A

a Assembly of multi-layer spheroid construct

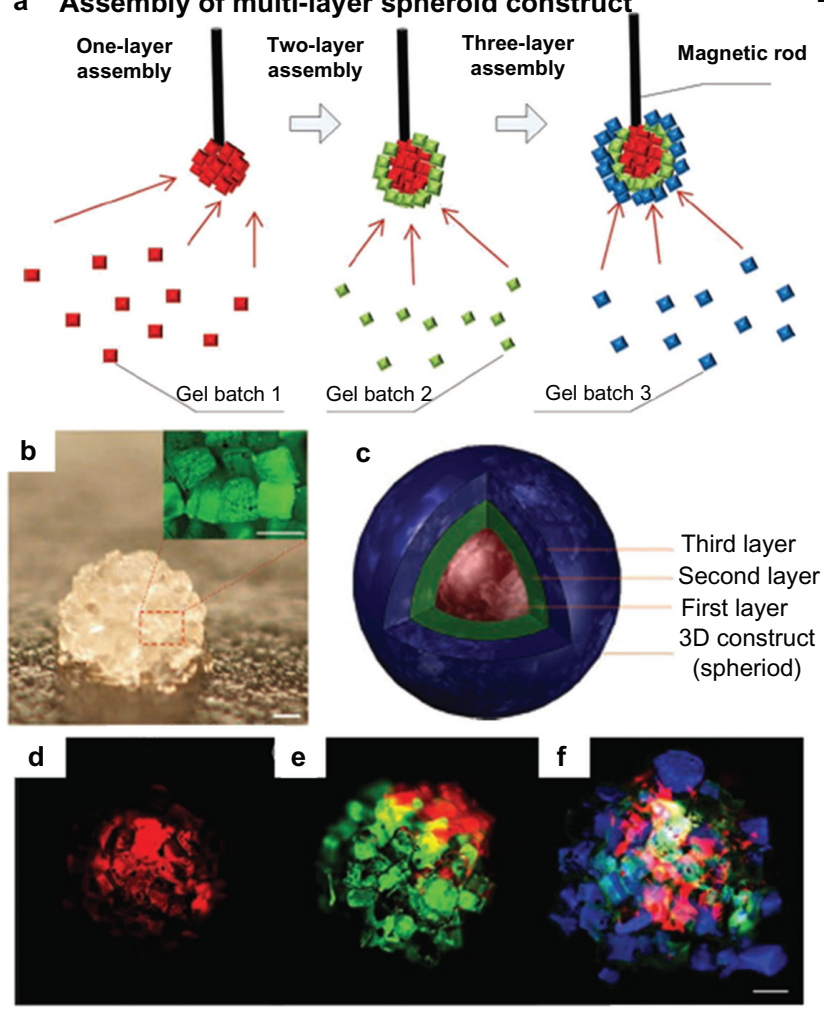

Scale bar: $500 \mu \mathrm{m}$
B
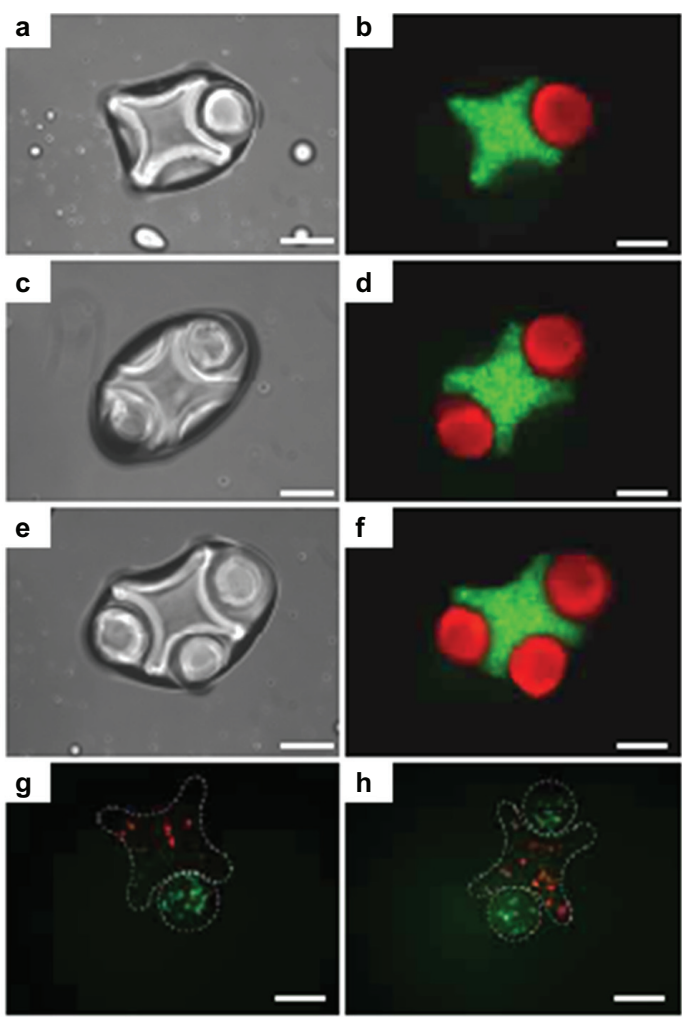

d

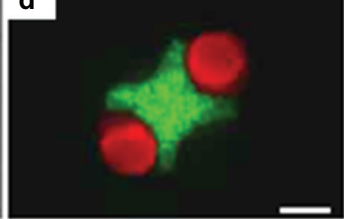

f

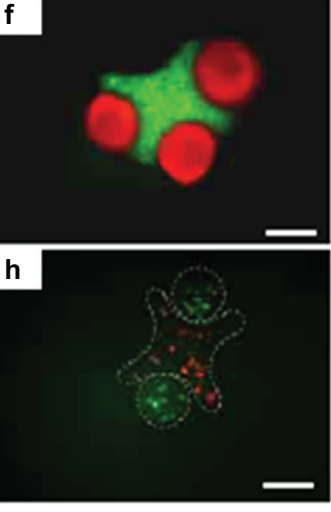

Scale bar: $200 \mu \mathrm{m}$

Figure 7 Magnetic and surface tension assembly of microgels. (A) (a) Schematic of magnetic assembly of microgels; (b) magnified image of the assembled single-layer construct (scale bar $500 \mu \mathrm{m}$ ); (c and f) merged fluorescent images of three-layer spheroids; first layer gels are stained with rhodamine B (d); second layer gels are stained with FITC-dextran (e); and third layer gels are stained with I, I, 4, 4-tetraphenyl-I,3-butadiene (f). Scale bar $500 \mu \mathrm{m} .{ }^{25}$ (B) Fluorescence images of lock-and-key assemblies with one, two, and three rods per cross (a to f); fluorescence images of assembled microgels containing green-stained and red-stained cells $\left(\mathbf{g}\right.$ and $\mathbf{~ h ) . ~ S c a l e ~ b a r ~} 200 \mu \mathrm{m} .{ }^{21}$

was linearly correlated with the M-gel biodegradation rate, with correlation factors of $0.96 \pm 0.03$ and $0.99 \pm 0.01$ for magnetic nanoparticle concentrations of $1 \% \mathrm{wt}$ and $5 \% \mathrm{wt}$, respectively. These results indicate that magnetic assembly of M-gels holds great potential for fabrication of threedimensional complex tissue constructs in vitro.

Compared with top-down tissue engineering strategies, the emerging approaches for assembly of cell-encapsulating microgels are promising for the engineering of spatially organized three-dimensional tissues and organs. However, several challenges still exist. For instance, more biocompatible and biodegradable polymers are needed to fabricate microgels for in vivo testing (eg, in situ implantation or injection). In addition, ways need to be found to enhance the mechanical properties of microgels intended for regeneration of specific tissues, such as bone and cartilage.

\section{Microfluidic hydrogels for vascularization}

One key challenge of the top-down approach to tissue engineering is the lack of a highly branched system of large blood vessels to supply oxygen and nutrients to the surrounding tissues. Hydrogels embedded in microfluidic networks have the potential to create functional tissues with enhanced vascularization and enable controlled cell behavior by regulating the distribution of chemical cues in hydrogels via microchannels. ${ }^{88,89}$ Various methods, including molding, soft lithography, and bioprinting can be utilized to engineer hydrogels embedded with microchannels. ${ }^{90-93}$ For instance, Huang et $\mathrm{al}^{94}$ fabricated hydrogels (PEG and agarose) embedded with mechanically enhanced microchannels using a simple molding method (Figure 8A). PEG was incorporated with agarose to create hydrogels having interpenetrating polymer networks using a two-step polymerization process. The mechanical properties of the microchannels generated were enhanced locally by an additional layer of PEG gelled onto the inner channel wall, which increased their resistance to surrounding pressure and deformation upon mechanical loading. The perfusion ability of microchannels has also been evaluated. Ling et a ${ }^{95}$ engineered microfluidic cell-encapsulating agarose hydrogels using a soft lithography approach (Figure 8B). Agarose solution mixed with hepatic cells was perfused and gelled against the templates fabricated by soft lithography. 
A

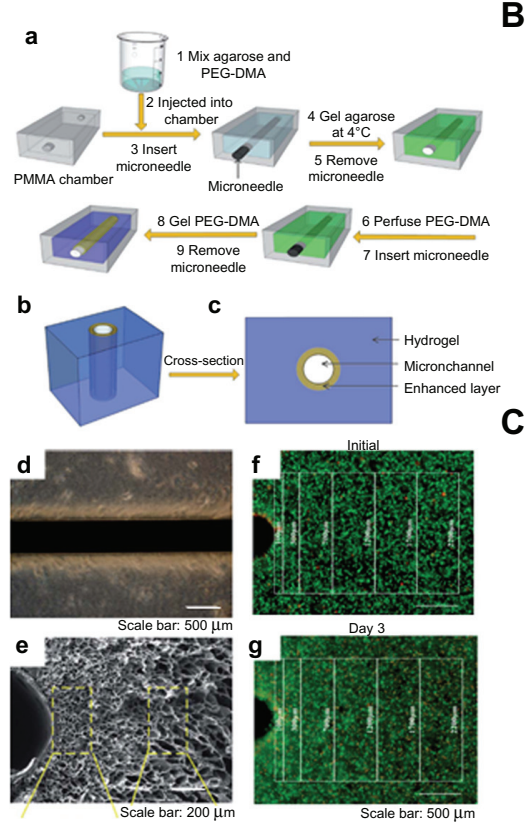

B

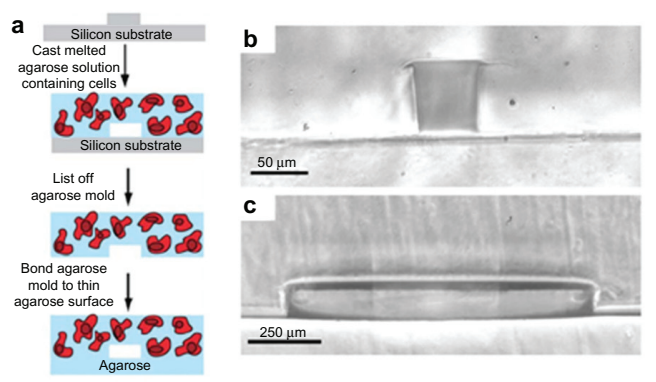

C a

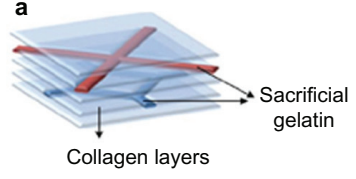

C

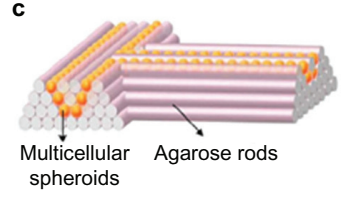

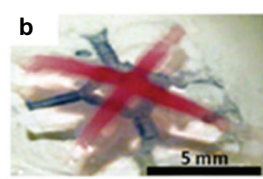

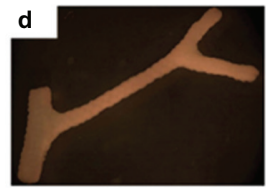

Figure 8 Microfluidic hydrogels for vascularization. (A) (a) Schematic representation of mechanically enhanced microfluidic hydrogel fabrication; (b) three-dimensional structure and (c) cross-sectional view; (d and e) hydrogels with enhanced microchannel wall. (d) Scale bar $500 \mu \mathrm{m}$; (e) scale bar $200 \mu \mathrm{m}$. (f and $\mathbf{g}$ ) Fluorescent images of live-dead cells following the fabrication process (f) and after 3 days of perfusion culture (g). Scale bar $500 \mu \mathrm{m} .{ }^{94}$ (B) (a) Schematic of fabrication process for microfluidic cell-encapsulating hydrogels (b and c) cross-sectional images of agarose constructs with channel size (b) $50 \mu \mathrm{m} \times 70 \mu \mathrm{m}$ and (c) I mm $\times 150 \mu \mathrm{m}$. (a) Scale bar $50 \mu \mathrm{m}$ and (b) scale bar $250 \mu \mathrm{m} .{ }^{95}$ (C) (a) Multilayered collagen scaffold with microfluidic microchannels; (b) utilizing printed gelatin networks as a sacrificial element. Scale bar 5 mm. (c and d) Designed post fusion pattern of branched constructs using agarose rods as filling material. ${ }^{96}$

Two sizes $(50 \mu \mathrm{m} \times 70 \mu \mathrm{m}$ and $1 \mathrm{~mm} \times 150 \mu \mathrm{m})$ of microchannels were generated, and it was shown that only the hepatic cells close to the channels remained viable after 3 days in culture, demonstrating the importance of a vascular-based structure in large hydrogel constructs. Lee et al ${ }^{96}$ generated multilayered cell-collagen constructs using a bioprinting technique (Figure 8C). They printed simultaneous gelatin networks as a sacrificial element, which were later thermally removed. Other branched constructs have also been fabricated by application of agarose rods acting as a filling material. ${ }^{97}$ Using this method, blood vessels of the desired geometry were constructed successfully.

Microfluidic hydrogels embedded within microfluidic networks can increase mass transfer and have the ability to regenerate vascularized tissue constructs in vitro. However, techniques for fabrication of hierarchically branched vascular

Table I Different methods for fabricating three-dimensional nanostructured scaffolds

\begin{tabular}{|c|c|c|c|c|c|c|c|}
\hline Method & Polymer & $\begin{array}{l}\text { Diameter } \\
\text { of fiber }\end{array}$ & Porosity & $\begin{array}{l}\text { Cell } \\
\text { viability }\end{array}$ & $\begin{array}{l}\text { Material types/ } \\
\text { commercially } \\
\text { available* }\end{array}$ & $\begin{array}{l}\text { Applications } \\
\text { for TE }\end{array}$ & Reference \\
\hline \multirow[t]{6}{*}{ Electrospinning } & PLLA & $400-1100 \mathrm{~nm}$ & $80 \%-95 \%$ & $<80 \%$ & $30 / \checkmark$ & Skin & $98-100$ \\
\hline & PLGA & & & & & Cartilage & 101 \\
\hline & PGA/PLLA & & & & & & 102 \\
\hline & Collagen/PCL & & & & & Vascular & 103 \\
\hline & Chitosan/PCL & & & & & Nerve & 104,105 \\
\hline & Silk/HAP & & & & & Bone & 106 \\
\hline \multirow[t]{3}{*}{ Phase-separation } & PLLA/HAP & $50-500 \mathrm{~nm}$ & $60 \%-98 \%$ & $<98 \%$ & $\mid 5-20 / \checkmark$ & Bone & 43,107 \\
\hline & PLGA & & & & & & 42 \\
\hline & Chitosan & & & & & & 44 \\
\hline \multirow[t]{3}{*}{ Freeze-drying } & Chitosan/PLLA & $50-450 \mathrm{~nm}$ & $30 \%-80 \%$ & $<90 \%$ & $15 / \sqrt{ }$ & Tendon & $108-110$ \\
\hline & Collagen/GAG & & & & & Bone/tendon & III \\
\hline & Gelatin-PHEMA & & & & & Skin & 49 \\
\hline Self-assembly & Peptide & $5-300 \mathrm{~nm}$ & $80 \%-90 \%$ & $60 \%-95 \%$ & $5-10 /-$ & Cartilage & 59,112 \\
\hline
\end{tabular}

Notes: *, approximate values; $\checkmark$, available; -, not known.

Abbreviations: PLLA, poly (lactic acid); PLGA, poly (lactic-co-glycolic acid); PGA, poly (glycolic acid); PCL, polycaprolactone; HAP, hydroxyapatite; GAG, glycosaminoglycan; PHEMA, poly ([MAG]-2-hydroxyethl methacrylate); TE, tissue engineering. 
networks in hydrogels need to be developed further. Moreover, it is still a big challenge to integrate microfluidic networks in fabricated tissue constructs with the host vascular system in vivo.

\section{Conclusion and future perspectives}

A variety of methods for fabrication of three-dimensional biomimetic scaffolds, including electrospinning, phaseseparation, freeze-drying, and self-assembly, have been developed for biomedical applications such as tissue engineering. These three-dimensional scaffolds offer great potential to mimic the native extracellular matrix due to their nanoscaled fibrous structures. Several thin or avascular tissues, such as skin, cartilage, and bladder, have been successfully engineered in vitro using both nanostructured scaffolds and a top-down approach. However, the lack of spatiotemporal control of the three-dimensional cellular microarchitecture and extracellular matrix distribution in large three-dimensional scaffolds presently limits their applications with regard to regeneration of complex functional tissues (eg, kidney and liver). In addition, how to generate a vascular system in three-dimensional scaffolds which can supply oxygen and nutrients to the encapsulated cells is also a big challenge.

Emerging bottom-up methods can fabricate threedimensional complex tissue constructs in vitro by assembling cell-encapsulating microgels. Compared with top-down approaches, there are several advantages: spatiotemporal control of three-dimensional complex constructs with desired geometry (eg, shape and multilayer); superior diffusion properties of microgels due to their controllable volume, resulting in a high cell density (greater than $80 \%$ ); and fabrication of vascular-like structures via microfluidic cell-encapsulating hydrogels, which are essential in a large tissue construct. The novel strategies reviewed here offer great potential to generate three-dimensional tissues and organs for clinical application.

\section{Acknowledgment}

This research was supported by the National Basic Research Program of China (973 Program, 2012CB619101) and the Natural Science Foundation of Shaanxi Province (2010JM2021).

\section{Disclosure}

The authors report no conflicts of interest in this work.

\section{References}

1. Chung SW, Ingle NP, Montero GA, Kim SH, King MW. Bioresorbable elastomeric vascular tissue engineering scaffolds via melt spinning and electrospinning. Acta Biomater. 2010;6:1958-1967.
2. Lao LH, Wang YJ, Zhu Y, Zhang YY, Gao CY. Poly(lactide-coglycolide)/hydroxyapatite nanofibrous scaffolds fabricated by electrospinning for bone tissue engineering. J Mater Sci Mater Med. 2011;22:1873-1884.

3. Soliman S, Pagliari S, Rinaldi A, et al. Multiscale three-dimensional scaffolds for soft tissue engineering via multimodal electrospinning. Acta Biomater. 2010;6:1227-1237.

4. Blaker JJ, Knowles JC, Day RM. Novel fabrication techniques to produce microspheres by thermally induced phase separation for tissue engineering and drug delivery. Acta Biomater. 2008;4:264-272.

5. Budyanto L, Goh YQ, Ooi CP. Fabrication of porous poly(L-lactide) (PLLA) scaffolds for tissue engineering using liquid-liquid phase separation and freeze extraction. J Mater Sci Mater Med. 2009;20:105-111.

6. Heijkants RGJC, Van Tienen TG, De Groot JH, et al. Preparation of a polyurethane scaffold for tissue engineering made by a combination of salt leaching and freeze-drying of dioxane. J Mater Sci. 2006;41: 2423-2428

7. Sultana N, Wang M. PHBV/PLLA-based composite scaffolds fabricated using an emulsion freezing/freeze-drying technique for bone tissue engineering: surface modification and in vitro biological evaluation. Biofabrication. 2012;4:015003.

8. Nagahama K, Ouchi T, Ohya Y. Temperature-induced hydrogels through self-assembly of cholesterol-substituted star PEG-b-PLLA copolymers: an injectable scaffold for tissue engineering. Adv Funct Mater. 2008; 18: $1220-1231$

9. Peck M, Dusserre N, McAllister TN, L'Heureux N. Tissue engineering by self-assembly. Mater Today. 2011;14:218-224.

10. Wei GB, Ma PX. Nanostructured biomaterials for regeneration. $A d v$ Funct Mater. 2008;18:3568-3582.

11. Groeber F, Holeiter M, Hampel M, Hinderer S, Schenke-Layland K. Skin tissue engineering - in vivo and in vitro applications. Clin Plast Surg. 2012;39:33-38.

12. Korossis S, Bolland F, Southgate J, Ingham E, Fisher J. Regional biomechanical and histological characterisation of the passive porcine urinary bladder: implications for augmentation and tissue engineering strategies. Biomaterials. 2009;30:266-275.

13. Wimpenny I, Ashammakhi N, Yang Y. Chondrogenic potential of electrospun nanofibres for cartilage tissue engineering. J Tissue Eng Regen Med. 2012;6:536-549.

14. Huang GY, Zhou LH, Zhang QC, et al. Microfluidic hydrogels for tissue engineering. Biofabrication. 2011;3:012001.

15. Malda J, Klein TJ, Upton Z. The roles of hypoxia in the in vitro engineering of tissues. Tissue Eng. 2007;13:2153-2162.

16. Rouwkema J, Rivron NC, van Blitterswijk CA. Vascularization in tissue engineering. Trends Biotechnol. 2008;26:434-441.

17. Nichol JW, Khademhosseini A. Modular tissue engineering: engineering biological tissues from the bottom up. Soft Matter. 2009;5: 1312-1319.

18. Napolitano AP, Chai P, Dean DM, Morgan JR. Dynamics of the selfassembly of complex cellular aggregates on micromolded nonadhesive hydrogels. Tissue Eng. 2007;13:2087-2094.

19. Yamato M, Okano T. Cell sheet engineering. Mater Today. 2004;7: $42-47$.

20. Tavana H, Mosadegh B, Takayama S. Polymeric aqueous biphasic systems for non-contact cell printing on cells: engineering heterocellular embryonic stem cell niches. Adv Mater. 2010;22:2628-2631.

21. Du YA, Lo E, Ali S, Khademhosseini A. Directed assembly of cell-laden microgels for fabrication of 3D tissue constructs. Proc Natl Acad Sci U S A. 2008;105:9522-9527.

22. Khademhosseini A, Langer R. Microengineered hydrogels for tissue engineering. Biomaterials. 2007;28:5087-5092.

23. Chung SE, Park W, Shin S, Lee SA, Kwon S. Guided and fluidic selfassembly of microstructures using railed microfluidic channels. Nat Mater. 2008;7:581-587.

24. Xu F, Finley TD, Turkaydin M, et al. The assembly of cell-encapsulating microscale hydrogels using acoustic waves. Biomaterials. 2011;32: $7847-7855$. 
25. Xu F, Wu C, Rengarajan V, et al. Three-dimensional magnetic assembly of microscale hydrogels. Adv Mater. 2011;23:4254-4460.

26. Zamanian B, Masaeli M, Nichol JW, et al. Interface-directed self-assembly of cell-laden microgels. Small. 2010;6:937-944.

27. Smith LA, Ma PX. Nano-fibrous scaffolds for tissue engineering. Colloids Surf B Biointerfaces. 2004;39:125-131.

28. Kuntz RM, Saltzman WM. Neutrophil motility in extracellular matrix gels: mesh size and adhesion affect speed of migration. Biophys $J$. 1997;72:1472-1480.

29. Reneker DH, Chun I. Nanometre diameter fibres of polymer, produced by electrospinning. Nanotechnology. 1996;7:216-223.

30. Li XY, Liu HC, Wang JN, Li CJ. Preparation and characterization of PLLA/nHA nonwoven mats via laser melt electrospinning. Mater Lett. 2012;73:103-106.

31. Park JS, Choi JB, Jo SY, et al. Characterization and structure analysis of PLGA/collagen nanofibrous membranes by electrospinning. $J$ Appl Polym Sci. 2012;125:595-603.

32. Chakrapani VY, Gnanamani A, Giridev VR, Madhusoothanan M, Sekaran G. Electrospinning of type I collagen and polycaprolactone nanofibers using acetic acid. J Appl Polym Sci. 2012;125:3221-3227.

33. Rho KS, Jeong L, Lee G, et al. Electrospinning of collagen nanofibers: effects on the behavior of normal human keratinocytes and early-stage wound healing. Biomaterials. 2006;27:1452-1461.

34. Luu YK, Kim K, Hsiao BS, Chu B, Hadjiargyrou M. Development of a nanostructured DNA delivery scaffold via electrospinning of PLGA and PLA-PEG block copolymers. J Control Release. 2003;89:341-353.

35. Li CM, Vepari C, Jin HJ, Kim HJ, Kaplan DL. Electrospun silk-BMP-2 scaffolds for bone tissue engineering. Biomaterials. 2006; 27:3115-3124.

36. Nolsoe H, Imer S, Hultin HO. Study of how phase separation by filtration instead of centrifugation affects protein yield and gel quality during an alkaline solubilisation process - different surimi-processing methods. Int J Food Sci Technol. 2007;42:139-147.

37. Guillen GR, Pan YJ, Li MH, Hoek EMV. Preparation and characterization of membranes formed by nonsolvent induced phase separation: a review. Ind Eng Chem Res. 2011;50:3798-3817.

38. Nam YS, Park TG. Biodegradable polymeric microcellular foams by modified thermally induced phase separation method. Biomaterials. 1999;20:1783-1790.

39. Shao JD, Chen C, Wang YJ, Chen XF, Du C. Early stage structural evolution of PLLA porous scaffolds in thermally induced phase separation process and the corresponding biodegradability and biological property. Polym Degrad Stabil. 2012;97:955-963.

40. O'Brien FJ. Biomaterials and scaffolds for tissue engineering. Mater Today. 2011;14:88-95.

41. Ma PX. Scaffolds for tissue fabrication. Mater Today. 2004;7:30-40.

42. Ma PX, Zhang RY. Synthetic nano-scale fibrous extracellular matrix. J Biomed Mater Res. 1999;46:60-72.

43. Ma PX, Zhang RY, Xiao GZ, Franceschi R. Engineering new bone tissue in vitro on highly porous poly(alpha-hydroxyl acids)/hydroxyapatite composite scaffolds. J Biomed Mater Res. 2001;54:284-293.

44. Zhao J, Han W, Chen H, et al. Preparation, structure and crystallinity of chitosan nano-fibers by a solid-liquid phase separation technique. Carbohydr Polym. 2011;83:1541-1546.

45. Pisano R, Barresi AA, Fissore D. Innovation in monitoring food freeze drying. Dry Technol. 2011;29:1920-1931.

46. Ganguly A, Nail SL, Alexeenko AA. Rarefied gas dynamics aspects of pharmaceutical freeze-drying. Vacuum. 2012;86:1739-1747.

47. Liu HH, Nakagawa K, Kato DI, Chaudhary D, Tade MO. Enzyme encapsulation in freeze-dried bionanocomposites prepared from chitosan and xanthan gum blend. Mater Chem Phys. 2011;129:488-494.

48. Autissier A, Le Visage C, Pouzet C, Chaubet F, Letourneur D. Fabrication of porous polysaccharide-based scaffolds using a combined freezedrying/cross-linking process. Acta Biomater. 2010;6:3640-3648.

49. Dragusin D-M, Van Vlierberghe S, Dubruel P, et al. Novel gelatinPHEMA porous scaffolds for tissue engineering applications. Soft Matter. 2012;8:9589-9602.
50. Whitesides GM, Grzybowski B. Self-assembly at all scales. Science. 2002;295:2418-2421.

51. Zhang SG, Gelain F, Zhao XJ. Designer self-assembling peptide nanofiber scaffolds for 3D tissue cell cultures. Semin Cancer Biol. 2005;15: 413-420.

52. Ma PX. Biomimetic materials for tissue engineering. Adv Drug Deliv Rev. 2008;60:184-198.

53. Stupp SI. Self-assembly and biomaterials. Nano Lett. 2010;10: 4783-4786.

54. Hartgerink JD, Beniash E, Stupp SI. Peptide-amphiphile nanofibers: a versatile scaffold for the preparation of self-assembling materials. Proc Natl Acad Sci U S A. 2002;99:5133-5318.

55. Hartgerink JD, Beniash E, Stupp SI. Self-assembly and mineralization of peptide-amphiphile nanofibers. Science. 2001;294:1684-1688.

56. Hamley IW. Self-assembly of amphiphilic peptides. Soft Matter. 2011;7:4122-4138.

57. Kumaraswamy P, Lakshmanan R, Sethuraman S, Krishnan UM. Self-assembly of peptides: influence of substrate, $\mathrm{pH}$ and medium on the formation of supramolecular assemblies. Soft Matter. 2011;7:2744-2754.

58. Zhang SG, Lockshin C, Herbert A, Winter E, Rich A. Zuotin, a putative Z-DNA binding-protein in Saccharomyces cerevisiae. EMBO J. 1992;11:3787-3796.

59. Liu JP, Song H, Zhang LL, Xu HY, Zhao XJ. Self-assembly-peptide hydrogels as tissue-engineering scaffolds for three-dimensional culture of chondrocytes in vitro. Macromol Biosci. 2010;10:1164-1170.

60. Luo ZL, Wang SK, Zhang SG. Fabrication of self-assembling D-form peptide nanofiber scaffold d-EAK16 for rapid hemostasis. Biomaterials. 2011;32:2013-2020.

61. Holmes TC. Novel peptide-based biomaterial scaffolds for tissue engineering. Trends Biotechnol. 2002;20:16-21.

62. Li MY, Mondrinos MJ, Gandhi MR, Ko FK, Weiss AS, Lelkes PI. Electrospun protein fibers as matrices for tissue engineering. Biomaterials. 2005;26:5999-6008.

63. Discher DE, Mooney DJ, Zandstra PW. Growth factors, matrices, and forces combine and control stem cells. Science. 2009;324:1673-1677.

64. Young JL, Engler AJ. Hydrogels with time-dependent material properties enhance cardiomyocyte differentiation in vitro. Biomaterials. 2011; 32:1002-1009.

65. Toh WS, Lim TC, Kurisawa M, Spector M. Modulation of mesenchymal stem cell chondrogenesis in a tunable hyaluronic acid hydrogel microenvironment. Biomaterials. 2012;33:3835-3845.

66. Engler AJ, Sen S, Sweeney HL, Discher DE. Matrix elasticity directs stem cell lineage specification. Cell. 2006;126:677-689.

67. Liu HF, Li XM, Zhou G, Fan HB, Fan YB. Electrospun sulfated silk fibroin nanofibrous scaffolds for vascular tissue engineering. Biomaterials. 2011;32:3784-3793.

68. Zhang YY, Yang F, Liu K, et al. The impact of PLGA scaffold orientation on in vitro cartilage regeneration. Biomaterials. 2012;33:2926-2935.

69. Wang XH, Yan YN, Zhang RJ. Recent trends and challenges in complex organ manufacturing. Tissue Eng Part B Rev. 2010;16:189-197.

70. Novosel EC, Kleinhans C, Kluger PJ. Vascularization is the key challenge in tissue engineering. Adv Drug Deliv Rev. 2011;63:300-311.

71. Phelps EA, Garcia AJ. Engineering more than a cell: vascularization strategies in tissue engineering. Curr Opin Biotechnol. 2010;21: 704-709.

72. Geckil H, Xu F, Zhang XH, Moon S, Demirci U. Engineering hydrogels as extracellular matrix mimics. Nanomedicine (Lond). 2010;5: 469-484.

73. Jensen BEB, Smith AAA, Fejerskov B, et al. Poly(vinyl alcohol) physical hydrogels: noncryogenic stabilization allows nano- and microscale materials design. Langmuir. 2011;27:10216-10223.

74. Gurkan UA, Tasoglu S, Kavaz D, Demirel MC, Demirci U. Emerging technologies for assembly of microscale hydrogels. Adv Healthc Mater. 2012;1:149-158.

75. Diez M, Schulte VA, Stefanoni F, et al. Molding micropatterns of elasticity on PEG-based hydrogels to control cell adhesion and migration. Adv Eng Mater. 2011;13:B395-B404. 
76. Qi H, Du YA, Wang LY, Kaji H, Bae HJ, Khademhosseini A. Patterned differentiation of individual embryoid bodies in spatially organized 3D hybrid microgels. Adv Mater. 2010;22:5276-5281.

77. Moon S, Hasan SK, Song YS, et al. Layer by layer three-dimensional tissue epitaxy by cell-laden hydrogel droplets. Tissue Eng Part $C$ Methods. 2010;16:157-166.

78. Park W, Lee H, Park H, Kwon S. Sorting directionally oriented microstructures using railed microfluidics. Lab Chip. 2009;9:2169-2175.

79. Chung SE, Jung Y, Kwon S. Three-dimensional fluidic self-assembly by axis translation of two-dimensionally fabricated microcomponents in railed microfluidics. Small. 2011;7:796-803.

80. Franke T, Braunmuller S, Schmid L, Wixforth A, Weitz DA. Surface acoustic wave actuated cell sorting (SAWACS). Lab Chip. 2010;10: 789-794.

81. Bourquin Y, Reboud J, Wilson R, Cooper JM. Tuneable surface acoustic waves for fluid and particle manipulations on disposable chips. $L a b$ Chip. 2010;10:1898-1901.

82. Yeo LY, Friend JR. Ultrafast microfluidics using surface acoustic waves. Biomicrofluidics. 2009;3:12002.

83. Cruise GM, Scharp DS, Hubbell JA. Characterization of permeability and network structure of interfacially photopolymerized poly(ethylene glycol) diacrylate hydrogels. Biomaterials. 1998;19:1287-1294.

84. Yagci Y, Sangermano M, Rizza G. In situ synthesis of gold-cross-linked poly(ethylene glycol) nanocomposites by photoinduced electron transfer and free radical polymerization processes. Chem Commun (Camb). 2008:2771-2773.

85. Ifkovits JL, Burdick JA. Review: photopolymerizable and degradable biomaterials for tissue engineering applications. Tissue Eng. 2007;13: 2369-2385.

86. Souza GR, Molina JR, Raphael RM, et al. Three-dimensional tissue culture based on magnetic cell levitation. Nat Nanotechnol. 2010;5: 291-296.

87. Xu F, Inci F, Mullick O, et al. Release of magnetic nanoparticles from cell-encapsulating biodegradable nanobiomaterials. ACS Nano. 2012;6:6640-6649.

88. Choi NW, Cabodi M, Held B, Gleghorn JP, Bonassar LJ, Stroock AD. Microfluidic scaffolds for tissue engineering. Nat Mater. 2007;6: 908-915.

89. Chung BG, Lee KH, Khademhosseini A, Lee SH. Microfluidic fabrication of microengineered hydrogels and their application in tissue engineering. Lab Chip. 2012;12:45-59.

90. Hatch A, Hansmann G, Murthy SK. Engineered alginate hydrogels for effective microfluidic capture and release of endothelial progenitor cells from whole blood. Langmuir. 2011;27:4257-4264.

91. Cuchiara MP, Allen ACB, Chen TM, Miller JS, West JL. Multilayer microfluidic PEGDA hydrogels. Biomaterials. 2010;31:5491-5497.

92. Golden AP, Tien J. Fabrication of microfluidic hydrogels using molded gelatin as a sacrificial element. Lab Chip. 2007;7:720-725.

93. Agarwal AK, Dong L, Beebe DJ, Jiang HR. Autonomously-triggered microfluidic cooling using thermo-responsive hydrogels. Lab Chip. 2007:7:310-315.

94. Huang G, Zhang X, Xiao Z, Zhang Q, Zhou J, Xu F, et al. Cell-encapsulating microfluidic hydrogels with enhanced mechanical stability. Soft Matter. 2012.
95. Ling Y, Rubin J, Deng Y, et al. A cell-laden microfluidic hydrogel. Lab Chip. 2007;7:756-762.

96. Lee W, Lee V, Polio S, et al. On-demand three-dimensional freeform fabrication of multi-layered hydrogel scaffold with fluidic channels. Biotechnol Bioeng. 2010;105:1178-1186.

97. Norotte C, Marga FS, Niklason LE, Forgacs G. Scaffold-free vascular tissue engineering using bioprinting. Biomaterials. 2009;30: 5910-5917.

98. Jin GR, Prabhakaran MP, Ramakrishna S. Stem cell differentiation to epidermal lineages on electrospun nanofibrous substrates for skin tissue engineering. Acta Biomater. 2011;7:3113-3122.

99. Chandrasekaran AR, Venugopal J, Sundarrajan S, Ramakrishna S. Fabrication of a nanofibrous scaffold with improved bioactivity for culture of human dermal fibroblasts for skin regeneration. Biomed Mater. 2011;6:015001.

100. Megelski S, Stephens JS, Chase DB, Rabolt JF. Micro- and nanostructured surface morphology on electrospun polymer fibers. Macromolecules. 2002;35:8456-8466.

101. Shin HJ, Lee CH, Cho IH, et al. Electrospun PLGA nanofiber scaffolds for articular cartilage reconstruction: mechanical stability, degradation and cellular responses under mechanical stimulation in vitro. J Biomat Sci Polym Ed. 2006;17:103-119.

102. You Y, Youk JH, Lee SW, Min BM, Lee SJ, Park WH. Preparation of porous ultrafine PGA fibers via selective dissolution of electrospun PGA/PLA blend fibers. Mater Lett. 2006;60:757-760.

103. Tillman BW, Yazdani SK, Lee SJ, Geary RL, Atala A, Yoo JJ. The in vivo stability of electrospun polycaprolactone-collagen scaffolds in vascular reconstruction. Biomaterials. 2009;30:583-588.

104. Yang WJ, Fu J, Wang DX, et al. Study on chitosan/polycaprolactone blending vascular scaffolds by electrospinning. J Biomed Nanotechnol. 2010;6:254-259.

105. Cooper A, Bhattarai N, Zhang MQ. Fabrication and cellular compatibility of aligned chitosan-PCL fibers for nerve tissue regeneration. Carbohydr Polym. 2011;85:149-156.

106. Wei K, Li Y, Kim KO, et al. Fabrication of nano-hydroxyapatite on electrospun silk fibroin nanofiber and their effects in osteoblastic behavior. J Biomed Mater Res A. 2011;97A:272-280.

107. Nishi T, Wang TT, Kwei TK. Thermally induced phase separation behavior of compatible polymer mixtures. Macromolecules. 1975;8: 227-234.

108. Niu XF, Li XM, Liu HF, et al. Homogeneous chitosan/poly(L-lactide) composite scaffolds prepared by emulsion freeze-drying. J Biomater Sci Polym Ed. 2012;23:391-404.

109. Cavalli R, Caputo O, Carlotti ME, Trotta M, Scarnecchia C, Gasco MR. Sterilization and freeze-drying of drug-free and drug-loaded solid lipid nanoparticles. Int J Pharm. 1997;148:47-54.

110. Boyde A, Franc F. Freeze-drying shrinkage of glutaraldehyde fixed liver. J Microsc. 1981;122:75-86.

111. Haugh MG, Murphy CM, O'Brien FJ. Novel freeze-drying methods to produce a range of collagen-glycosaminoglycan scaffolds with tailored mean pore sizes. Tissue Eng Part C Methods. 2010;16:887-894.

112. Castelletto V, Hamley IW, Adamcik J, Mezzenga R, Gummel J. Modulating self-assembly of a nanotape-forming peptide amphiphile with an oppositely charged surfactant. Soft Matter. 2012;8:217-226.
International Journal of Nanomedicine

\section{Publish your work in this journal}

The International Journal of Nanomedicine is an international, peerreviewed journal focusing on the application of nanotechnology in diagnostics, therapeutics, and drug delivery systems throughout the biomedical field. This journal is indexed on PubMed Central, MedLine, CAS, SciSearch ${ }^{\circledR}$, Current Contents ${ }^{\circledR} /$ Clinical Medicine,

\section{Dovepress}

Journal Citation Reports/Science Edition, EMBase, Scopus and the Elsevier Bibliographic databases. The manuscript management system is completely online and includes a very quick and fair peer-review system, which is all easy to use. Visit http://www.dovepress.com/ testimonials.php to read real quotes from published authors. 